\title{
The Appropriate Time Interval Between Hysteroscopic Polypectomy and the Start of FET : A Retrospective Corchort Study
}

\section{Zhong-Kai Wang}

Zhengzhou University Third Hospital and Henan Province Women and Children's Hospital Hong-Wu Qiao

Zhengzhou University Third Hospital and Henan Province Women and Children's Hospital

\section{She-Ling Wu}

Zhengzhou University Third Hospital and Henan Province Women and Children's Hospital

\section{Wen Zhang}

Zhengzhou University Third Hospital and Henan Province Women and Children's Hospital

\section{Xiao-Na Yu}

Zhengzhou University Third Hospital and Henan Province Women and Children's Hospital Jing Li

Zhengzhou University Third Hospital and Henan Province Women and Children's Hospital

\section{Xing-Ling Wang}

Zhengzhou University Third Hospital and Henan Province Women and Children's Hospital

\section{Hua Lou}

Zhengzhou University Third Hospital and Henan Province Women and Children's Hospital Yi-Chun Guan ( $\square$ lisamayguan1@126.com )

Zhengzhou University Third Hospital and Henan Province Women and Children's Hospital https://orcid.org/0000-0002-0312-3984

\section{Research}

Keywords: Endometrial polyps, hysteroscopy, polypectomy, Frozen-embryo transfer, timing

Posted Date: November 19th, 2020

DOI: https://doi.org/10.21203/rs.3.rs-110131/v1

License: (c) (1) This work is licensed under a Creative Commons Attribution 4.0 International License. Read Full License 


\section{Abstract}

Objective: To investigate when is the appropriate time interval between hysteroscopic polypectomy and the start of FET cycles

Design: Retrospective cohort study.

Setting: Academic center.

Patient(s): All patients diagnosed with endometrial polyps undergoing hysteroscopic polypectomy before FET.

Intervention(s): Hysteroscopic polypectomy.

MainOutcomeMeasure(s): Patients were divided into four groups based on the time interval between hysteroscopic polypectomy and the start of FET Demographics, baseline FET characteristics, pregnancy outcomes after FET were compared among the groups. A total of 1703 patients met inclusion criteria: 547 patients in group 1 who underwent FET after hysteroscopic polypectomy 1-3menses cycles, 389 patients in group 2 who underwent FET after hysteroscopic polypectomy 4-6 menses cycles, 421 patients in group 3 who underwent FET after hysteroscopic polypectomy 7-12menses cycles, and 373 patients in group 4 who underwent FET after hysteroscopic polypectomy more than 12 menses cycles, whats more the group 1 were divided into 3 groups depend on the time interval between hysteroscopic polypectomy and the start of FET. The FET outcomes were compared.

Result(s): There were no differences in the mean number of embryos transferred. The overall pregnancy outcomes were similar for groups 1 , 2, 3,and 4: implantation rate $(38 \%, 38.2 \%, 39.5 \%$ and 36.8 , respectively), clinical pregnancy rate $(51.9 \%, 48 \%, 53.2$ and $50 \%)$, spontaneous miscarriage rate $(8.4 \%, 8.4 \%, 12.2$ and $8.9 \%)$, and live birth rate $(42.4 \% .40 .4 \%, 42.8 \%$ and $40.9 \%)$.

Conclusion(s): IVF outcomes seem to be unrelated to the time interval between the hysteroscopic polyp resection and the initiation of the FET; The abortion rates may be lower if the treatment is started in the first few months post operatively.

\section{Introduction}

Embryo quality and uterine receptivity are the two most important factors for a successful implantation in in vitro fertilization (IVF) cycles. Although localized lesions of the endometrium that are commonly seen in women of reproductive age (1). It is clear that removal of endometrial polyps can help to increase natural conception rates as well as increase pregnancy rates with the use of assisted reproduction (2-7). But the best appropriate interval between the hysteroscopic polyp resection there are less data regarding the appropriate time interval between polyp resection and start of assisted reproduction treatment (8). In our study, we aimed to compared the FET outcomes of the time interval between hysteroscopic polypectomy and the start of Frozen-embryo transfer (FET) cycles. 


\section{Materials And Methods}

Inclusion and Exclusion Criteria in The Third Affiliated Hospital of Zhengzhou university College Institutional Review Board approved the study protocol. All patients diagnosed with endometrial polyps undergoing hysteroscopic polypectomy before FET cycles from January 2016 to December 2019 were analyzed for potential inclusion. Inclusion criteria includede Endometrial polyps were diagnosed by hysteroscopy. Endometrial polyp was usually suspected by hyperechoic with regular occupied the uterine cavity either partially or fully $(7,9)$.we selected patients who were not older than 43 years during the FET cycles and patients who BMI were less than $30 \mathrm{~kg} / \mathrm{m} 2$ Exclusion criteria included donor oocyte cycles, PGD/PGS who had systemic health problems or who were using antidiabetic, antihypertensive, or steroidtype medications were not included the study. Cycles and patients with recurrent IVF failure.

\section{Hysteroscopic polypectomy}

Hysteroscopic polypectomy was carried out in the follicular phase of

the subsequent menstrual cycle by the same physician with bearing an outer diameter of $8 \mathrm{~mm}$ The surgery was undertaken using a cutting-loop without the application of diathermy. All visible endometrial polyps were bluntly removed under direct hysteroscopic vision.

\section{Clinical and Laboratory Protocols}

For the preparation of patients in the natural cycle group, the follicles were followed up with USG at intervals of 3 to 4 days from the beginning of the cycle. When the dominant follicle was greater than 17 mm, u-hCG $10000 \mathrm{U}$ or r-hCG 250 ug was administered. Progesterone was started 36 hours later, and natural progesterone (Crinone vaginal gel, Merck Serono, Switzerland) was used for 3 days in patients whose embryos were frozen on the third day and for 5 days in patients whose embryos were frozen on the fifth day, at $90 \mathrm{mg}$ once a day. The embryos were transferred on the following day, and progesterone was continued in the women who became pregnant until the 10th to 12th week of pregnancy. The patients in the HRT cycle group were administered transdermal estrogen The patients, whose doses were increased by 1 patch at intervals of 4 days, underwent USG on the 14th day of their cycle. The patients with an endometrial thickness of more than $8 \mathrm{~mm}$ started to receive vaginal natural progesterone (Crinone vaginal gel, Merck Serono) in the morning and at night on the following day (day 15).

Following the 3-day progesterone (90 $\mathrm{mg}$ twice a day) use in patients whose embryos were frozen on the third day before transfer and 5-day progesterone use for those whose embryos were frozen on the fifth day before transfer, the embryos were thawed and transferred on the following day. After the transfer, estrogen and progesterone use was continued for 14 days until the beta-hCG test. Estrogen and progesterone use was continued in women who became pregnant until the 10th-12th week of pregnancy.

\section{Outcome Variables}


Demographic characteristics recorded included age, body mass index (BMl; $\mathrm{kg} / \mathrm{m} 2$ ). Baseline FET characteristics recorded were FSH $(\mathrm{mlU} / \mathrm{mL})$ and E2 $(\mathrm{pg} / \mathrm{mL})$ level at cycle start, peak endometrial stripe $(\mathrm{mm})$, mean number of embryos transferred (10). Pregnancy outcomes after FET were also recorded. Implan tation rate was defined as the mean number of gestational sacs seen with the use of transvaginal ultrasonography divided by the number of embryos transferred for each patient. Clinical pregnancy rate was defined as the number of intrauterine gestations with fetal cardiac activity per FET cycle. A biochemical pregnancy was defined as positive hCG level. Any pregnancy loss after visualization of an intrauterine gestation was considered to be a spontaneous miscarriage, and any birth after 24 weeks of gestation was considered to be a live birth.

\section{Statistical Analyses}

All statistical analyses were performed with the use of SPSS 23 Continuous variables were checked for normality and expressed as mean \pm SD. Categoric variables were expressed as $\mathrm{n}(\%)$. By study design, patients were as signed to four groups based on the time interval between hysteroscopic polypectomy and the start of a FET cycle: Group 1 consisted of patients who underwent FET after their 1-3menses, group 2 after 4-6 menstrual cycles, group 3after 7-12 menstrual cycles group 4 after more than 12 menstrual cycles. Analysis of variance and chi-square tests were used to compare means and percentages of recorded parameters among the four groups. Statistical significance was set at $P<0.05$.

\section{Results}

A total of 1977 patients underwent hysteroscopies during the study period. The 1703 patients who met inclusion criteria were grouped as follows: 547 in group $1 \varangle 389$ in group $2 \varangle 421$ in group 3and 373 in group 4.Whats more the group 1 were divided into 3 groups depend on the time interval between hysteroscopic polypectomy and the start of FET The FET outcomes were compared.

Table 1 compares the demographic and baseline FET characteristics of patients undergoing FET cycles after hysteroscopic polypectomy, stratified by number of menstrual cycles. The mean ages of patients in groups 1 , 2,3and 4 were $(32.1 \pm 4.98$ years, $32.2 \pm 4.79$ years, $32.6 \pm 4.9$ years and $32.9 \pm 4.77)$, respectively. Similarly to mean age, there was no statistical difference in Pcos $\bigotimes$ Ovulatory dysfunction, or BMI of the three groups composing the study cohort. Furthermore, there was no difference in the basal FSH level or basal E2 level at FET start.

Table 2 compares the outcomes of FET cycles of patients undergoing IVF cycles after hysteroscopic polypectomy, stratified by number of menstrual cycles. The mean numbers of embryos transferred were similar among the groups. There was no difference in implantation rates(38\%, 38.2\%, 39.5\%and $36.8 \%$,p0.819),clinical pregnancy rates $(51.9 \%, 48 \%, 53.2 \%$ and $50 \%$; P0.474), spontaneous miscarriage rates $(8.4 \%, 8.4 \%, 12.2 \%$ and $8.9 \%$; P0.111), or live birth rates $(42.4 \%, 40.4 \%, 42.8 \%$ and $40.9 \%$ P0.93) when comparing the four groups there were no sinificant diference of 
Table 3 The group 1 were divided into 3 subgroups depend on the time interval between hysteroscopic polypectomy and the start of FET The FET outcomes were compared.compares the demographic and baseline FET characteristics of patients undergoing FET cycles after hysteroscopic polypectomy, stratified by number of menstrual cycles. The mean ages of patients in subgroups 1, 2 and 3 were $31.7 \pm 4.7$ years, $32.7 \pm 5.18$ years and $32.1 \pm 5.13$, respectively. There was no difference in implantation rates(39.4\%, 35.4\%and 39.1\%,p0.557), clinical pregnancy rates $(52.7 \%, 47.4 \%$ and $55.7 \%, p 0.314)$, spontaneous miscarriage rates $(4.9 \%, 9.8 \%, 12.2 \% \bigotimes \mathrm{P} 0.033)$, and live birth rates $(49.3 \%$, $39.4 \%, 49.5 \%$ and $40.9 \% \mathrm{P} 0.051)$

\section{Discussion}

Endometrial polyps are localized overgrowths of endometrial glands and stroma within the uterine cavity.In determining uterine receptivity, the endometrium and uterine cavity are two important factors

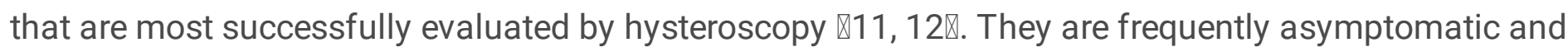
therefore may remain undetected $₫ 13 \bigotimes$.

The prevalence of endometrial polyps is considered to be higher in infertile women $(1,14)$. The polyps can be millimeters to centimeters in size, single or multiple, and sessile or pedunculated,(15). Some studies suggest that polyps are associated with infertility (15), but only one randomized controlled trial confirms the association. (7). It seems that many of the risk factors for endometrial polyps can be underlied by unopposed or excess estrogen exposure, as in the case of ovarian stimulation during $\operatorname{IVF}(4,9,10)$. Molecular mechanisms, containing the over expression of estrogen and progesterone receptors (25), Polyps may adversely affect fertility by mechanically interfering with sperm transportation or as spaceoccupying lesions impeding embryo implantation $(4,5)$. Endometrial polyps may also induce local inflammatory changes $(19,20)$ or produce glycodelin $(21)$, The glands and stroma in endometrial polyps are unresponsive to progesterone stimulation, leading to defective implantation at the site of the polyp $(20,22)$ With respect to endometrial receptivity, HOXA10 and HOXA11 mRNA expression are decreased in endometrium obtained from uterine cavities containing polyps compared with normal cavities, (15).

In this context, hysteroscopic polypectomy remains the criterion standard for both diagnosis and treatment of endometrial polyps $(1,15)$. Previous studies have shown that resection of endometrial polyps can improve natural conception rates, particularly in patients with unexplained infertility (16). In one retrospective study of 78 patients by Varasteh et al, a pregnancy rate of $78.3 \%$ was noted after polypectomy compared with a pregnancy rate of $42.1 \%$ in patients with normal uterine cavities (6). Removal of polyps at the uterotubal junction results in the greatest chance of pregnancy (57.4\%) based on a retrospective study of polyp location in 230 infertile women [23]. The best evidence for polyps as a cause for infertility comes from a well designed RCT of 215 infertile women with polyps planning to undergo intrauterine insemination (IUI) [24]..Significantly higher pregnancy rates were demonstrated in women who had hysteroscopic polypectomy 
Pregnancy rates are also improved in patients undergoing hysteroscopic polypectomy before undergoing intrauterine insemination (IUI) $(9,15)$.Similarly, a previous retrospective study showed that natural conception rates were increased among infertile women who had hysteroscopic polypectomy compared with those who had hysteroscopy, but were found to have a normal cavity (78 versus $42.1 \%$ ) $₫ 25 \rrbracket$. These findings were confirmed by another independent study, which reported pregnancy rates of $40.7 \%$ and $22.3 \%$ in patients who, respectively, did and did not undergo polypectomy before IUI (2). The resection of endometrial polyps diagnosed before starting IVF-ET cycles are suppored by current evidence. (1). However, there is limited evidence about the optimal time interval between hysteroscopic polypectomy and initiation of a FET cycle. In a retrospective study of 60 patients, Eryilmaz et al. compared the ovarian stimulation and pregnancy outcomes of 29 and 31 patients who got IVF $<6$ months and 6 months, respectively, after hysteroscopic polypectomy . It is concluded that there is no relation between the IVF outcomes of the study cohort and the initiation time of the IVF after the hysteroscopic polypectomy (8). Whereas our study stratified the time period between polypectomy and FET cycle start by the number of intervening menstrual cycles. It is suggested by some studies that higher implantation and pregnancy rates after mild endometrial injury in the menstrual cycle preceding IVF (27). Group 1 in the present study represents such a clinical scenario, but the implantation and pregnancy rates of group 1 were similar to those of groups $2 \varangle 3$ and 4 . The present study is not without limitations. All hysteroscopic polypectomy cases were performed in the operating room with the use of a monopolar resectoscope. It remains to be confirmed whether the observed IVF-ET cycle outcomes would remain unchanged if polypectomy were operated in the office setting or with other resection methods, such as bipolar electrode excision (29) or hysteroscopic morcellation $(30,31)$. Although our analysis of FETcycle outcomes was stratified on the basis of the number of menstrual cycles between hysteroscopic polypectomy and FET cycle start, Furthermore, it must be noted that reasons for delaying FET were largely logistical or personal. Finally, its conclusions should be interpreted with caution and should be subject to larger prospective settings, because the study was retrospective in nature.

\section{Conclusion}

The data from this study suggest that FET outcomes seem to be unrelated to the time interval between the hysteroscopic polyp resection and the initiation of the FET; The abortion rates may be lower if the treatment is started in the first few months post operatively. This approach may be especially beneficial in patients who require specific timing of FET cycles.

\section{Abbreviations}

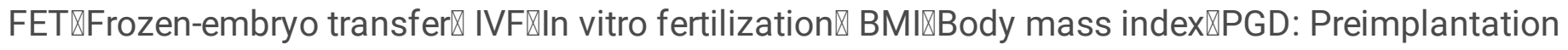
genetic diagnosis; PGS: Preimplantation genetic screening; u-hCG】

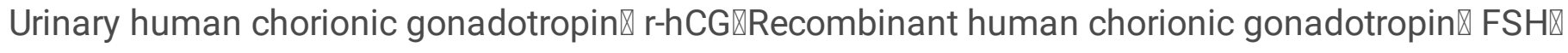

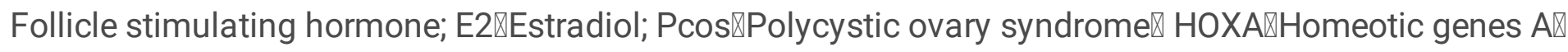




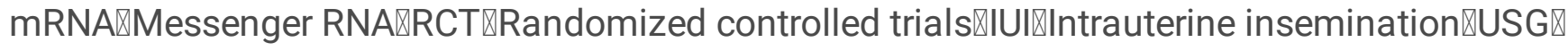

Ultrasonography.

\section{Declarations}

\section{Acknowledgements}

The authors thank all of medical staffs in the Center for Reproductive Medicine, Zhengzhou University Third Hospital and Henan Province Women and Children's Hospital, China for recording all the data in this study through the years.

\section{Authors' contributions}

Zhong-Kai Wang and Hong-Wu Qiao contributed to the conception and design. Zhong-Kai Wang and Hong-Wu Qiao conntributed to statistical analyzing andg article writing. She-Ling Wu contributed to data collection. Jing-Li, Lou-Hua, Xing-Ling Wang, Wen-Zhang, Xiao-Na Yu, Yi-Chun Guan contributed to revising the article critically for important intellectual content. All authors read and approved the final version of the manuscript.

\section{Funding}

This work was supported by grant [17020320701] from the Special fund for clinical research of the Chinese Medical Association: Protective effects and molecular mechanism of sRAGE on inhibiting inflammation and improving insulin resistance in PCOS; the Special fund for clinical research of Chinese Medical Association.

\section{Availability of data and materials}

The datasets used and analyzed during the current study are available from the corresponding author on reasonable request.

\section{Ethics approval and consent to participate}

The study was performed in accordance with guidelines outlined in the Declaration of Helsinki. All the methods and information collection protocols were approved by the institutional review board of Zhengzhou University Third Hospital and Henan Province Women and Children's Hospital, China. Our research has obtained the waiver from institutional review board for the medical review for selective variable analysis in the center.

\section{Competing interests}

The authors declare no competing interests.

\section{Author details}


1 Center for Reproductive Medicine, Zhengzhou University Third Hospital and Henan Province Women and Children's Hospital, China

2.Department of Obstetrics and Gynecology, Zhengzhou University Third Hospital and Henan Province Women and Children's Hospital, China

\section{References}

1. American Association of Gynecologic Laparoscopists. AAGL practice report: practice guidelines for the diagnosis and management of endometrial polyps. J Minim Invasive Gynecol 2012;19:3-10.

2. Kalampokas T, Tzanakaki D, Konidaris S, lavazzo C, Kalampokas E, Gregoriou O. Endometrial polyps and their relationship in the pregnancy rates of patients undergoing intrauterine insemination. Clin Exp Obstet Gynecol 2012;39:299-302.

3. Bosteels J, Kasius J, Weyers S, Broekmans FJ, Mol BW, D'Hooghe TM. Treat- ing suspected uterine cavity abnormalities by hysteroscopy to improve repro- ductive outcome in women with unexplained infertility or prior to IUI, IVF, or ICSI. Gynecol Surg 2013;10:165-7.

4. Lass A, Williams G, Abusheikha N, Brinsden P. The effect of endometrial polyps on outcomes of in vitro fertilization (IVF) cycles. J Assist Reprod Genet 1999;16:410-5.

5. Stamatellos I, Apostolides A, Stamatopoulos P, Bontis J. Pregnancy rates af- ter hysteroscopic polypectomy depending on the size or number of the polyps. Arch Gynecol Obstet 2008;277:395-9.

6. Varasteh NN, Neuwirth RS, Levin B, Keltz MD. Pregnancy rates after hysteroscopic polypectomy and myomectomy in infertile women. Obstet Gynecol 1999;94:168-71.

7. P_x0019_erez-Medina T, Bajo-Arenas J, Salazar F, Redondo T, Sanfrutos L, Alvarez P, et al. Endometrial polyps and their implication in the pregnancy rates of patients undergoing intrauterine insemination: a prospective, randomized study. Hum Reprod 2005;20:1632-5.

8. Eryilmaz OG, Gulerman C, Sarikaya E, Yesilyurt H, Karsli F, Cicek N. Appr priate interval between endometrial polyp resection and the proceeding IVF start. Arch Gynecol Obstet 2012;285:1753-7.

9. Elias RT, Pereira N, Karipcin FS, Rosenwaks Z, Spandorfer SD. Impact of newly diagnosed endometrial polyps during controlled ovarian hyperstimu- lation on in vitro fertilization outcomes. $J$ Minim Invasive Gynecol 2015;22: 590-4.

10. Pereira N, Hutchinson AP, Bender JL, Lekovich JP, Elias RT, Rosenwaks Z, et al. Is ABO blood type associated with ovarian stimulation response in patients with diminished ovarian reserve? J Assist Reprod Genet 2015;32: 985-90.

11. Taylor E, Gomel V (2008) The uterus and fertility. Fertil Steril 89:1-16.

12. Bettocci S, Nappi L, Ceci O (2004) OYce hysteroscopy. Obstet Gynecol Clin North Am 31:641-654

13. Hassa $H$, Tekin B, Senses $T$, et al. Are the site, diameter, and number of endometrial polyps related with symptomatology? Am J Obstet Gynecol 2006; 194:718-721. 
14. Haimov-Kochman R, Deri-Hasid R, Hamani Y, Voss E. The natural course of endometrial polyps: could they vanish when left untreated? Fertil Steril 2009;92:828.e11-2.

15. Pereira N, Petrini AC, Lekovich JP, Elias RT, Spandorfer SD. Surgical manage-ment of endometrial polyps in infertile women: a comprehensive review. Surg Res Pract 2015;2015:914390.

16. Saccardi C, Gizzo S, Ludwig K, Guido M, Tinelli R, Litta PS, et al. Endometrial polyps in women affected by levothyroxine-treated hypothyroidism-histological features, immunohistochemical fifindings, and possible explanation of etiopathogenic mechanism: a pilot study. Biomed Res Int 2013;2013: 503419.

17. Rackow BW, Jorgensen E, Taylor HS. Endometrial polyps affect uterine receptivity. Fertil Steril 2011;95:2690-2.

18. Taylor E, Gomel V. The uterus and fertility. Fertil Steril 2008;89:1-16.

19. Al-Jefout M, Black K, Schulke L, Berbic M, Manconi F, Fraser IS, et al. Novel fifinding of high density of activated mast cells in endometrial polyps. Fertil Steril 2009;92:1104-6.

20. Inagaki N, Ung L, Otani T, Wilkinson D, Lopata A. Uterine cavity matrix metalloproteinases and cytokines in patients with leiomyoma, adeno- myosis or endometrial polyp. Eur J Obstet Gynecol Reprod Biol 2003; 111:197-203.

21. Richlin SS, Ramachandran S, Shanti A, Murphy AA, Parthasarathy S. Gly- codelin levels in uterine flushings and in plasma of patients with leio- myomas and polyps: implications for implantation. Hum Reprod 2002; 17:2742-7.

22. Al-Jefout M, Black K, Schulke L, Berbic M, Manconi F, Fraser IS, et al. Novel finding of high density of activated mast cells in endometrial polyps. Fertil Steril 2009;92:1104-6.

23. Yanaihara A, Yorimitsu T, Motoyama $\mathrm{H}$, et al. Location of endometrial polyp and pregnancy rate in infertility patients. Fertil Steril 2008; 90:180-182.

24. Perez-Medina T, Bajo-Arenas J, Salazar F, et al. Endometrial polyps and their implication in the pregnancy rates of patients undergoing intrauterine insemination: a prospective, randomized study. Hum Reprod 2005; 20:1632- 1635

25. Yanaihara A, Yorimitsu T, Motoyama $\mathrm{H}$, et al. Location of endometrial polyp and pregnancy rate in infertility patients. Fertil Steril 2008; 90:180-182.

26. Perez-Medina T, Bajo-Arenas J, Salazar F, et al. Endometrial polyps and their implication in the pregnancy rates of patients undergoing intrauterine insemination: a prospective, randomized study. Hum Reprod 2005; 20:1632- 1635

27. Varasteh NN, Neuwirth RS, Levin B, Keltz MD. Pregnancy rates after hysteroscopic polypectomy and myomectomy in infertile women. Obstet Gynecol 1999; 94:168-

28. Gnainsky Y, Granot I, Aldo PB, Or Y, Mor G, Dekel N, et al. Local injury of the endometrium induces an inflammatory response that promotes successful implantation. Fertil Steril 2010;94:2030-6.

29. Nastri CO, Lensen SF, Gibreel A, Ferriani RA, Martins WP, Bhattacharya S, et al. Endometrial injury in women undergoing assisted reproductive tech- niques. Cochrane Database Syst Rev 
2015:CD009517.

30. Golan A, Sagiv R, Berar M, Ginath S, Glezerman M. Bipolar electrical energy in physiologic solution-a revolution in operative hysteroscopy. J Am Assoc Gynecol Laparosc 2001;8:252-8.

31. Emanuel MH, Wamsteker $\mathrm{K}$. The Intra Uterine Morcellator: a new hysteroscopic operating technique to remove intrauterine polyps and myomas. J Minim Invasive Gynecol 2005;12:62-6.

\section{Tables}

Table 1

\begin{tabular}{|c|c|c|c|c|c|}
\hline & $1-3 M$ & $4-6 \mathrm{M}$ & $7-12 M$ & प्रा2M & $\mathbf{P}$ \\
\hline & $N=556$ & $N=389$ & $\mathrm{~N}=421$ & $N=373$ & \\
\hline Age(y) & $32.1 \pm 4.98$ & $32.2 \pm 4.79$ & $32.6 \pm 4.9$ & $32.9 \pm 4.77$ & 0.039 \\
\hline $\begin{array}{l}\text { Body mass } \\
\text { Index }(\mathrm{kg} / \mathrm{m} 2)\end{array}$ & $23.5 \pm 2.67$ & $23.5 \pm 2.65$ & $23.8 \pm 2.79$ & $23.5 \pm 2.67$ & 0.123 \\
\hline bFSH (IU/I) & $7.25 \pm 6.90$ & $6.97 \pm 3.74$ & $7.07 \pm 3.68$ & $7.49 \pm 5.32$ & 0.534 \\
\hline bLH(IU/L) & $5.34 \pm 3.46$ & $5.18 \pm 3.21$ & $5.31 \pm 2.45$ & $5.24 \pm 2.56$ & 0.892 \\
\hline bE2(ng/ml) & $49.77 \pm 55.37$ & $44.73 \pm 50.52$ & $40.38 \pm 15.74$ & $45.38 \pm 40.74$ & 0.275 \\
\hline AFC & $15.2 \pm 7.40$ & $15.3 \pm 7.41$ & $14.9 \pm 7.15$ & $14.5 \pm 7.61$ & 0.428 \\
\hline $\begin{array}{l}\text { No.of embryos } \\
\text { transferred }\end{array}$ & $1.6 \pm 0.50$ & $1.6 \pm 0.50$ & $1.6 \pm 0.51$ & $1.6 \pm 0.51$ & 0.922 \\
\hline $\begin{array}{l}\text { Endometrium } \\
\text { thickness, day of FET } \\
(\mathrm{mm})\end{array}$ & $9.9 \pm 1.79$ & $9.9 \pm 1.85$ & $9.8 \pm 1.76$ & $9.5 \bigotimes 1.78$ & 0.002 \\
\hline PCOS(\%) & $\begin{array}{l}12.2 \\
\varangle 67 / 547 \rrbracket\end{array}$ & $\begin{array}{l}11.5 \\
\varangle 44 / 381 \rrbracket\end{array}$ & 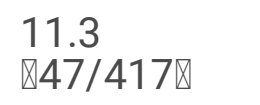 & 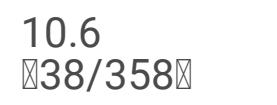 & 0.897 \\
\hline $\begin{array}{l}\text { Ovulatory dysfunction } \\
\bigotimes \% \bigotimes\end{array}$ & 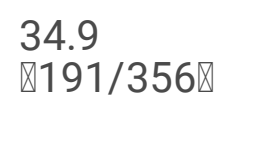 & $\begin{array}{l}29.4 \\
\otimes 112 / 381 \rrbracket\end{array}$ & $\begin{array}{l}27.3 \\
\otimes 114 / 303 \rrbracket\end{array}$ & $\begin{array}{l}27.9 \\
\rrbracket 100 / 258 \rrbracket\end{array}$ & 0.039 \\
\hline EMT囚\%区 & $\begin{array}{l}10.4 \\
\otimes 57 / 547 \rrbracket\end{array}$ & 7.6ه29/381】 & 7.2ه30/417凹 & $9.5 \rrbracket 34 / 358 \rrbracket$ & 0.260 \\
\hline D3凶\%》 & $\begin{array}{l}45.3 \\
\otimes 248 / 547 \rrbracket\end{array}$ & 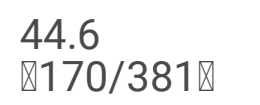 & $\begin{array}{l}40.5 \\
₫ 169 / 417 \rrbracket\end{array}$ & $\begin{array}{l}45 \\
\otimes 161 / 358 \rrbracket\end{array}$ & 0.452 \\
\hline
\end{tabular}

Table 2 


\begin{tabular}{|c|c|c|c|c|c|}
\hline & $\begin{array}{l}1-3 M \\
N=556\end{array}$ & $\begin{array}{l}3-6 M \\
N=389\end{array}$ & $\begin{array}{l}6-12 M \\
N=421\end{array}$ & $\begin{array}{l}\mathrm{N}=373 \\
\mathrm{~N}=3 \mathrm{M}\end{array}$ & $\mathbf{P}$ \\
\hline $\begin{array}{l}\text { Biochemical } \\
\text { Prengancy }(\% \rrbracket\end{array}$ & $56.1(307 / 547)$ & $52.2(199 / 381)$ & $57.1(238 / 417)$ & 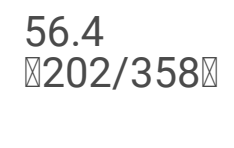 & 0.517 \\
\hline $\begin{array}{l}\text { Implantation rate in } \\
\text { FET(\%) }\end{array}$ & $38 \rrbracket 325 / 855 \rrbracket$ & $38.2(227 / 595)$ & $39.5(256 / 648)$ & $\begin{array}{l}36.8 \\
\varangle 310 / 570 \rrbracket\end{array}$ & 0.819 \\
\hline $\begin{array}{l}\text { No.of embryos } \\
\text { transferred }\end{array}$ & $1.78 \pm 0.41$ & $1.70 \pm 0.46$ & $1.72 \pm 0.45$ & $1.73 \pm 0.47$ & 0.255 \\
\hline Prengnancy rates $₫ \bigotimes$ & $51.9(284 / 547)$ & $48(183 / 381)$ & $53.2(222 / 417)$ & $\begin{array}{l}50 \\
\otimes 179 / 358 \rrbracket\end{array}$ & 0.474 \\
\hline Abortion rate $\otimes \% \bigotimes$ & $8.4(46 / 547)$ & $8.4(32 / 381)$ & $12.2(51 / 417)$ & $\begin{array}{l}8.9 \\
\otimes 32 / 358 \rrbracket\end{array}$ & 0.111 \\
\hline Live birth rate $₫ \% \bigotimes$ & $42.4(158 / 373)$ & $40.4(103 / 255)$ & $42.8(116 / 271)$ & $\begin{array}{l}40.9 \\
\varangle 88 / 215 \rrbracket\end{array}$ & 0.933 \\
\hline
\end{tabular}

Table 3 


\begin{tabular}{|c|c|c|c|c|}
\hline & $\begin{array}{l}1 \mathrm{M} \\
\mathrm{N}=\mathbf{2 2 6}\end{array}$ & $\begin{array}{l}2 \mathrm{M} \\
\mathrm{N}=173\end{array}$ & $\begin{array}{l}3 \mathrm{M} \\
\mathrm{N}=148\end{array}$ & $\mathbf{P}$ \\
\hline $\operatorname{Age}(\mathrm{y})$ & $31.7 \pm 4.7$ & $32.7 \pm 5.18$ & $32.1 \pm 5.13$ & 0.128 \\
\hline $\begin{array}{l}\text { Body mass } \\
\text { Index }(\mathrm{kg} / \mathrm{m} 2)\end{array}$ & $23.5 \pm 2.79$ & $23.8 \pm 2.66$ & $23.9 \pm 2.71$ & 0.411 \\
\hline bFSH (IU/I) & $8.04 \pm 2.40$ & $6.5 \pm 2.39$ & $7.1 \pm 3.33$ & 0.081 \\
\hline bLH(IU/L) & $5.34 \pm 3.46$ & $5.18 \pm 3.21$ & $5.31 \pm 2.45$ & 0.892 \\
\hline bE2(ng/ml) & $49.77 \pm 55.37$ & $44.73 \pm 50.52$ & $40.38 \pm 15.74$ & 0.422 \\
\hline AFC & $14.8 \pm 7.38$ & $15.3 \pm 7.19$ & $15.6 \pm 7.83$ & 0.559 \\
\hline No.of embryos transferred & $1.5 \pm 0.50$ & $1.6 \pm 0.49$ & $1.5 \pm 0.50$ & 0.541 \\
\hline $\begin{array}{l}\text { Endometrium thickness, day of FET } \\
(\mathrm{mm})\end{array}$ & $10.0 \pm 1.7$ & $9.8 \pm 1.86$ & $9.8 \pm 1.81$ & 0.433 \\
\hline D3凶\%》 & 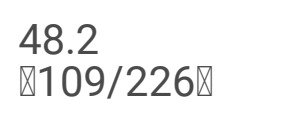 & $45.1(78 / 173 \rrbracket$ & 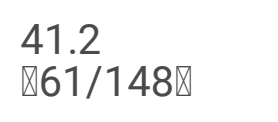 & 0.410 \\
\hline $\begin{array}{l}\text { Biochemical } \\
\text { Prengancy(\%区 }\end{array}$ & $56.6(128 / 226)$ & $52.0(90 / 173)$ & $60.1(89 / 148)$ & 0.337 \\
\hline Implantation rate in FET(\%) & 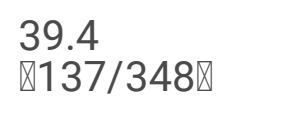 & $35.4(97 / 274)$ & $39.1(91 / 142)$ & 0.557 \\
\hline Prengnancy rates $\llbracket \% \bigotimes$ & $52.7(119 / 226)$ & $47.4(82 / 173)$ & $55.7(83 / 149)$ & 0.314 \\
\hline Abortion rate $\% \bigotimes$ & $4.9(11 / 226)$ & $9.8(17 / 173)$ & $12.2(18 / 148)$ & 0.033 \\
\hline Live birth rate $\varangle \% \bigotimes$ & $49.3(75 / 152)$ & $34.4(44 / 128)$ & $49.5(46 / 93)$ & 0.021 \\
\hline
\end{tabular}

\section{Figures}




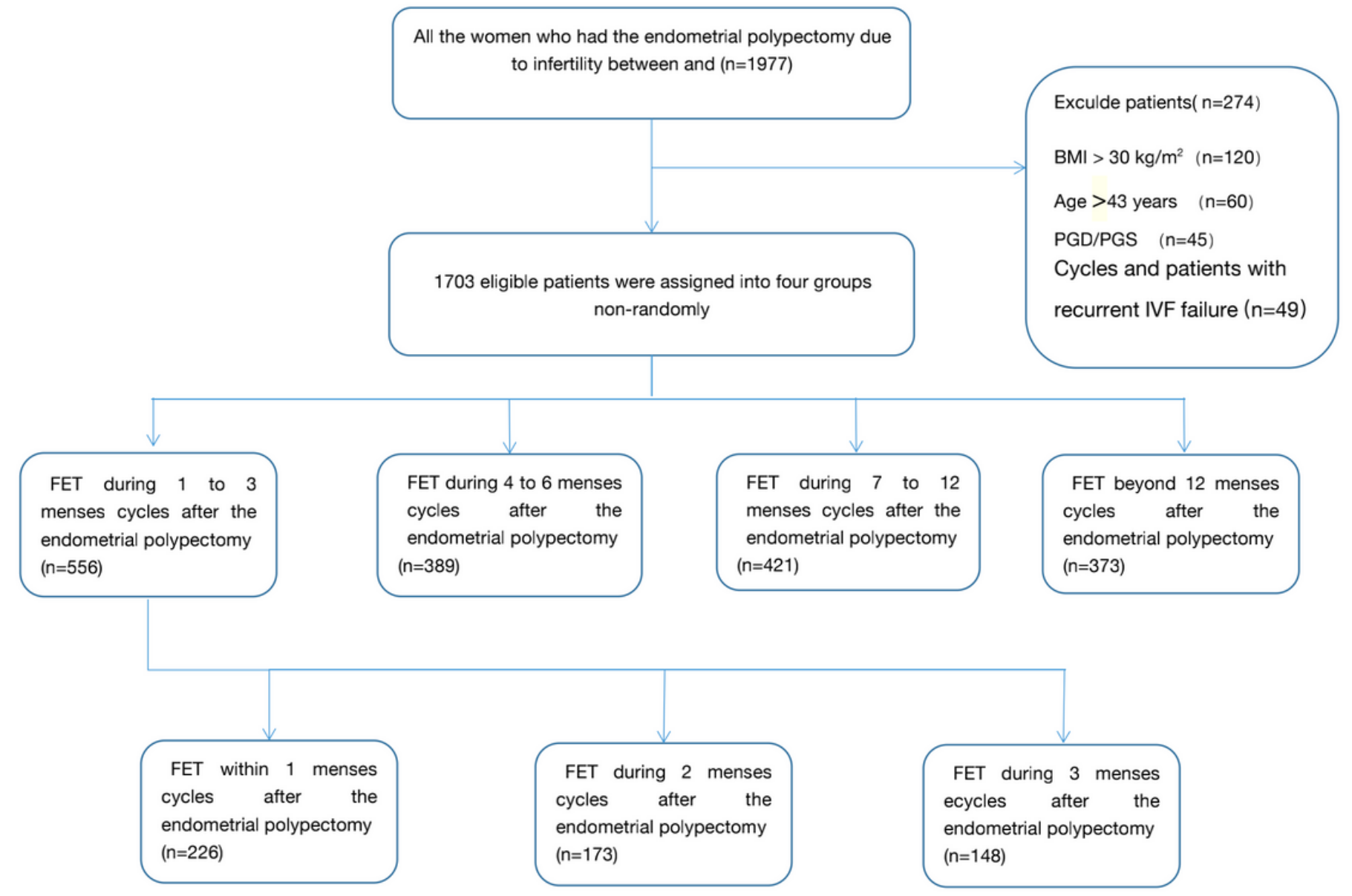

\section{Figure 1}

Design routes 


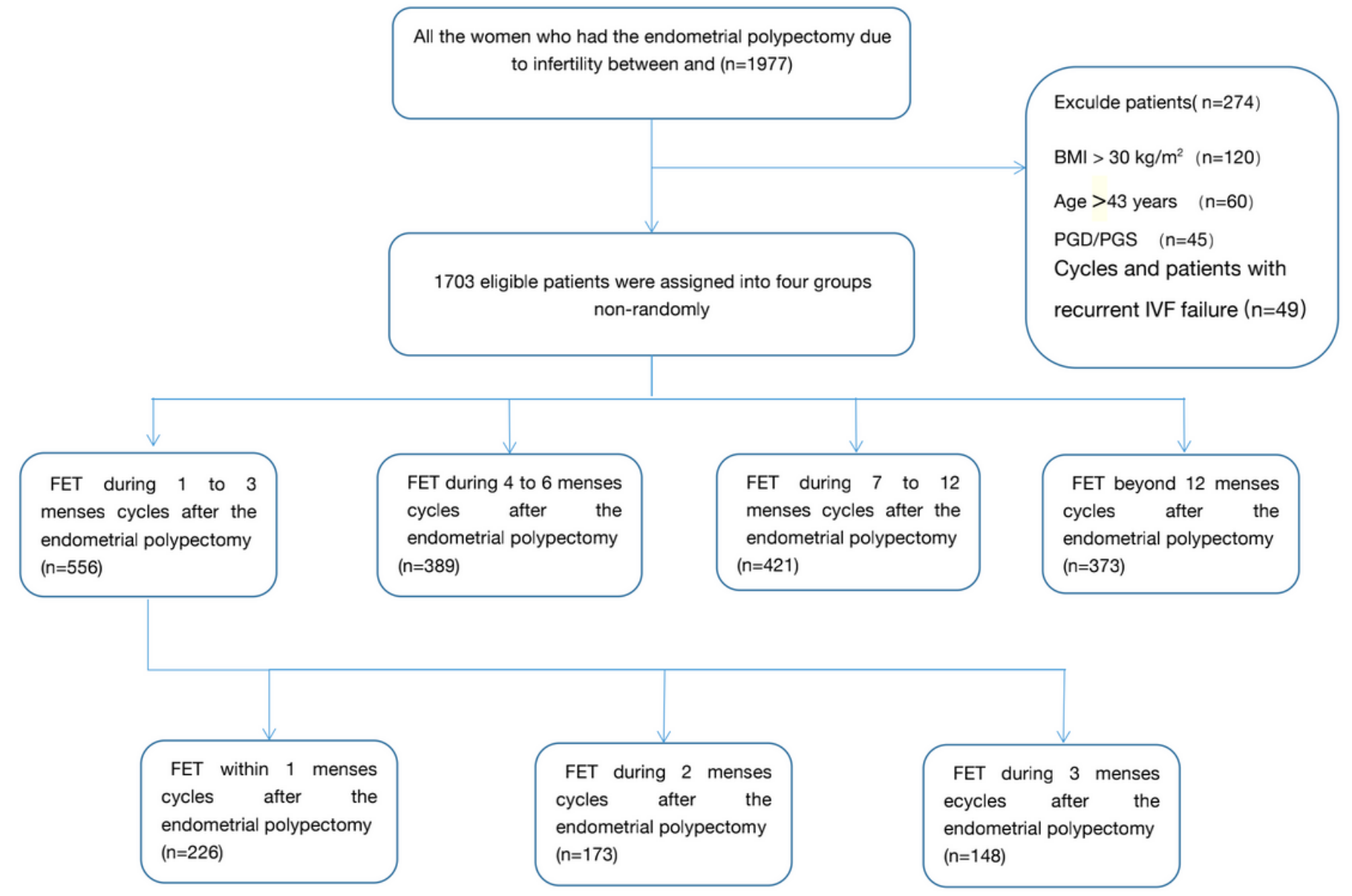

\section{Figure 1}

Design routes 